\title{
Sindicatos de bibliotecários: história e atuação
}

\author{
Librarians' unions: history and practice
}

\author{
Daniela Fernanda Assis Oliveira SPUDEIT1,3 \\ Fabiane FÜHR ${ }^{2,3}$
}

\section{Resumo}

O presente artigo propõe uma discussão acadêmico-científica, na qual busca apresentar contribuições relevantes sobre a história e evolução dos sindicatos de bibliotecários, visando revelar a atual situação em que estes órgãos se encontram no Brasil. O movimento sindical, como instrumento de defesa dos direitos dos trabalhadores, vem evoluindo desde o Século XIX e impõe regras e limites para patrões e empregados. No Brasil, o sindicalismo surgiu inicialmente no meio rural e se fortaleceu durante o governo de Getúlio Vargas (1930-1945) e com a Consolidação das Leis do Trabalho, em maio de 1943, impulsionando a criação de sindicatos profissionais. Porém, somente na década de 1980, os sindicatos de Bibliotecários surgiram nos estados de Bahia, Minas Gerais, São Paulo, Paraná e Rio de Janeiro. Os demais sindicatos, nos estados de Maranhão, Santa Catarina, Pará, Amapá e Tocantins foram criados a partir dos anos 2000. Atualmente, existem três sindicatos de bibliotecários ativos, situados em São Paulo, Rio de Janeiro e no Paraná, sendo que existe um no Estado de Santa Catarina em processo de estruturação. Por meio de uma pesquisa bibliográfica e exploratória, conseguiu-se mapear e analisar a situação e a evolução dos sindicatos de bibliotecários atualmente. Percebem-se as dificuldades para estruturação e manutenção destes órgãos no país e a necessidade da participação ativa dos profissionais bibliotecários dentro dos sindicatos para o fortalecimento de sua própria profissão, visando garantir seus direitos e valorização da profissão pela sociedade.

Palavras-chave: Sindicalização. Sindicato. Sindicalismo no Brasil. Sindicato de bibliotecários.

\begin{abstract}
This paper proposes an academic and scientific discussion which seeks to present relevant contributions on the history and evolution of librarians' unions, with the aim of unveiling the current status of these organs in Brazil. The trade union movement, as a means of defending workers'rights, has been evolving since the nineteenth century and imposes rules and limitations for both employers and employees. In Brazil, trade unions firstemerged in rural areas and became strong during the government of Getúlio Vargas (1930-1945) and with the Consolidation of Labor Laws (CLT) in May 1943, driving the creation of professional unions. However it was only in the 1980 that the Librarians' unions emerged in the states of Bahia, Minas Gerais, São Paulo, Paraná and Rio de Janeiro. The other unions in the states of Maranhão, Santa Catarina, Pará, Amapá and Tocantins were created after 2000. Currently, there are three active librarians' unions, Iocated in São Paulo, Rio de Janeiro and Paraná and there is one in the state of Santa Catarina on the drawing board. By means of an exploratory search of the literature, we were able to map and analyze the situation and the evolution of librarians' unions today. Difficulties could be seen with the structuring and maintenance of these organs in the country and the need for active participation of professional librarians within the trade unions to strengthen their own profession in order to guarantee their rights and the recognition of the profession by society.
\end{abstract}

Keywords: Unionization. Union. Unionism in Brazil. Librarians'union.

1 Bibliotecária, SENAC Santa Catarina. Florianópolis, SC, Brasil.

2 Bibliotecária, SENAI Santa Catarina. Tubarão, SC, Brasil.

3 Diretoras, Associação Catarinense de Bibliotecários. Av. Josué Di Bernardi, 239, Ed. Jowi, Sala 302, 88101-200, Campinas, São José, SC, Brasil. Correspondência para/Correspondence to: F. FÜHR. E-mail: <fabifuhr@gmail.com>.

Recebido em 13/3/2011, reapresentado em 18/7/2011 e aceito para publicação em 2/9/2011.

TransInformação, Campinas, 23(3):235-249, set./dez., 2011 


\section{Introdução}

O movimento sindical origina-se da busca do homem por condições de trabalho mais justas e humanas em uma sociedade capitalista em ascensão. Sindicato é toda instituição, ou associação, em regra, de caráter profissional, que tem por objetivo a defesa dos interesses comuns de uma classe, ou de um grupo de pessoas, ligadas entre si pelos mesmos interesses. Instituindo-se para defesa de interesses de trabalhadores ou de pessoas de classes, qualifica-se como sindicato profissional (De Plácido e Silva, 1982).

Os sindicatos têm se estruturado de maneira a atender as necessidades de seus filiados. Atualmente, os sindicatos estão atuando e apoiando diferentes classes de trabalhadores e são divididos em dois grupos: rurais e urbanos (este subdividido em empregados, trabalhadores autônomos, profissionais liberais e trabalhadores avulsos) e, há também os sindicatos patronais, que defendem o equilíbrio de interesses das empresas e dos empregados de diferentes profissões e ocupações.

A Biblioteconomia é uma profissão regulamentada pela Lei n. 4.084, de 30 de junho de 1962, que dispõe sobre seu exercício. O Decreto n. 56.725, de 16 de agosto de 1965 destaca em seu Artigo $2^{\circ}$ que a designação profissional do bibliotecário foi incluída no quadro das profissões liberais da Consolidação das Leis do Trabalho (CLT). Entre as principais forças de ação da classe bibliotecária no país, existem a Federação Brasileira de Associações de Bibliotecários, Cientistas da Informação e Instituições (FEBAB), fundada em julho de 1959 e o Conselho Federal de Biblioteconomia (CFB), criado em dezembro de 1965. Sendo que cabe à FEBAB a promoção de capacitação e educação continuada dos profissionais, e cabe ao Conselho Federal de Biblioteconomia a fiscalização da profissão.

Entretanto, as representações para a defesa dos interesses trabalhistas dos bibliotecários cabem aos sindicatos. Para compreender como os sindicatos de bibliotecários surgiram e se desenvolveram no Brasil, foi realizada uma pesquisa bibliográfica e exploratória onde se buscou fazer a análise da literatura de acordo com a ótica de alguns dos principais pesquisadores brasileiros, tais como Rodrigues (1968), Canêdo (1988) e Vianna (1989).
Além dos dados estatísticos da Central Única de Trabalhadores (CUT) e do Departamento Intersindical de Estatística e Estudos Socioeconômicos (DIEESE) que apresentam informações relevantes para compreender as questões sociais e políticas que abarcam um processo de sindicalização, buscaram-se dados documentais em sindicatos, conselhos e associações de bibliotecários no país para efetuar o mapeamento e análise da atuação dos sindicatos de bibliotecários brasileiros.

Martorano (1984) foi uma bibliotecária pioneira no estudo sobre sindicatos de bibliotecários. Segundo essa autora, esse debate foi iniciado em 1970 por Laura Russo, então Presidente da Federação Brasileira de Associações de Bibliotecários, Cientistas da Informação e Instituições. Porém, somente em julho de 1982 foi criada uma comissão, chamada Assessoria de Valorização e Divulgação Profissional, vinculado à FEBAB, para fazer um estudo de viabilidade sobre a sindicalização da profissão, cujo resultado foi apresentado durante o XII Congresso Brasileiro de Biblioteconomia e Documentação, comprovando essa necessidade. Foi na década de 1980 que surgiram os primeiros sindicatos de bibliotecários no Brasil.

Deste modo, o trabalho que originou o presente artigo teve por objetivo propor uma discussão acadêmico-científica, na qual busca apresentar contribuições relevantes sobre a história e evolução dos sindicatos de bibliotecários, visando revelar a atual situação em que estes órgãos se encontram no Brasil. Em face deste objetivo, aborda o surgimento e desenvolvimento dos sindicatos no mundo, com ênfase na origem e funcionamento dos sindicatos existentes no Brasil, órgãos e legislações que regem a atuação dessas entidades e, por fim, analisa o desenvolvimento, as funções e atuação dos sindicatos de bibliotecários no país, enfatizando a necessidade da participação ativa dos profissionais bibliotecários dentro dos sindicatos para o fortalecimento de sua própria profissão, visando garantir seus direitos e valorização da profissão pela sociedade.

\section{Métodos}

O processo de pesquisa se constitui em uma atividade científica básica que, através da indagação e (re)construção da realidade, alimenta a atividade de ensino e a atualiza frente à realidade. Assim como vincula pensa- 
mento e ação, já que "nada pode ser intelectualmente um problema se não tiver sido, em primeiro lugar, um problema da vida prática" (Minayo, 2001, p.17).

Ao iniciar os estudos para implantação de um sindicato de bibliotecários no Estado de Santa Catarina (SC), percebeu-se a reduzida quantidade de publicações acadêmico-científicas a esse respeito na literatura científica. Com grandes dificuldades, a Comissão Pró-SindBiblio/SC começou fazendo todos os encaminhamentos para a criação deste órgão, mas existia a falta de informação documentada acerca de outros sindicatos existentes e também sobre a quantidade de bibliotecários atuantes no estado de Santa Catarina. Com o auxílio prestimoso do Sindicato de Bibliotecários de São Paulo, do Conselho Regional de Biblioteconomia de Santa Catarina, da Febab e do Conselho Federal de Biblioteconomia, é que se conseguiu ter acesso a algumas informações, porém, algumas contraditórias.

Perante estas dificuldades, percebeu-se a importância de resgatar estes dados sobre a história, criação, desenvolvimento e atuação dos sindicatos de bibliotecários no Brasil buscando com este artigo trazer contribuições relevantes para uma discussão acadêmico-científica acerca da importância desses sindicatos para a integração destes profissionais e valorização da profissão pela sociedade.

Durante o estudo, optou-se por fazer uma pesquisa bibliográfica e exploratória, por meio do contato com membros das gestões dos sindicatos e, principalmente, em documentos publicados por instituições que foram registrados em atas de reuniões e no próprio site dos órgãos de classe da Biblioteconomia.

O objetivo de uma pesquisa exploratória é familiarizar-se com um assunto ainda pouco conhecido, pouco explorado. Ao final de uma pesquisa exploratória, é possível conhecer mais sobre aquele assunto, e o sujeito estará apto a construir hipóteses. Como qualquer pesquisa, ela depende também de uma pesquisa bibliográfica, pois mesmo que existam poucas referências sobre o assunto pesquisado, haverá sempre alguma obra, ou entrevista com pessoas que tiveram experiências práticas com problemas semelhantes ou análise de exemplos análogos que podem estimular a compreensão (Gil, 2008).
Lima e Mioto (2007) destacam que, ao tratar da pesquisa bibliográfica, é importante enfatizar que ela é sempre realizada para fundamentar teoricamente o objeto de estudo, contribuindo com elementos que subsidiam a análise futura dos dados obtidos. Portanto, difere da revisão bibliográfica uma vez que vai além da simples observação de dados contidos nas fontes pesquisadas, pois imprime sobre eles a teoria, a compreensão crítica do significado neles existente.

A pesquisa bibliográfica deve ser vista como um procedimento metodológico importante na produção do conhecimento científico, capaz de gerar, especialmente em temas pouco explorados, a postulação de hipóteses ou interpretações que servirão de ponto de partida para outras pesquisas (Lima; Mioto, 2007, p.44).

Para o resgate histórico dos sindicatos no mundo e no País, foi realizado um exaustivo e profundo levantamento de informações e dados publicados em livros, artigos de revistas, bases de dados e em sites de diferentes instituições. Para a coleta de dados foram feitas entrevistas via correio eletrônico com membros das gestões dos conselhos regionais, sindicatos, associações de Biblioteconomia, além de usar documentos, boletins, atas de reuniões e os próprios sites das entidades como base para o levantamento de informações, já que esta foi a principal motivação desta pesquisa, em face das poucas publicações e consistência dos dados relacionados à criação e desenvolvimento dos sindicados de bibliotecários no País.

\section{O surgimento dos sindicatos}

A história da sociedade é marcada pela luta entre opressores e oprimidos, explorados e exploradores, patrões e empregados, resultantes do sistema escravista, feudal ou capitalista, a luta de classes existe há muitos séculos. Os sindicatos surgiram a partir da necessidade de representação dessas classes. Segundo Canêdo (1988, p.11), sindicato é "uma associação destinada a defender, junto aos empregadores e ao Estado, os interesses dos trabalhadores assalariados de uma mesma profissão".

Na Idade Média, as corporações de ofício podiam ser consideradas as origens dos primeiros sindicatos, pois reuniam os donos da produção (mestres) e os trabalhadores (aprendizes). Na Idade Moderna, com a Revolução Industrial, houve uma intensa tentativa de organização 
do movimento sindicato laboral com a criação de uma associação de trabalhadores alfaiates, na Inglaterra, e a edição do decreto D’Allarde, na França, indo da repressão à livre constituição das organizações sindicais (Pimentel, 2010).

Entretanto, os sindicatos ganharam mais força somente no Século XIX, quando houve a ampliação dos direitos de cidadania para trabalhadores. Foi nesse período, segundo Vianna (1989, p.7), que ocorreu um"conjunto de transformações que induziram a uma reorientação do papel do Estado, a redefinição do privado diante da ordem pública e a intervenção legal no mercado de trabalho através da criação do Direito do Trabalho".

Segundo Vianna (1989, p.23) "o direito do trabalho emerge como uma conquista da classe trabalhadora contra o pacto original do liberalismo, impondo limites legais externos". Durante esse período, a regulamentação da jornada de trabalho, entre outros direitos adquiridos nessa época, se apresentaram, na história da produção capitalista, como uma luta pela limitação da jornada de trabalho, em um embate que se trava entre a classe capitalista e a classe trabalhadora.

Para compreender como aconteceu o processo de criação e desenvolvimento dos sindicatos de bibliotecários no Brasil, faz-se necessário apresentar um resgate histórico sobre a origem dos sindicatos conforme será apresentado a seguir.

\section{Origem do sindicalismo no Brasil}

O sindicalismo no Brasil tem origem no período do Império; (Russomano, 2002, p.30) "no Rio de Janeiro, foram fundadas algumas entidades, como a Liga Operária (1870) e a União Operária (1880), que se propunham a congregar e defender os trabalhadores". No Brasil, até 1889 não havia qualquer tipo de controle do mercado de trabalho, embora as ações operárias e sindicais tivessem liberdade, ainda não tinham condições para interferir na regulamentação do trabalho. O período de 1891 a 1919 foi um momento caracterizado pela legislação dos sindicatos ${ }^{4}$ apesar do baixo nível de ação e de organização do movimento operário e sindical, houve a legitimação de atividades de resistência com a admissão do direito de associação. Nesse período, o mercado livre até então passou a sofrer influência do Estado e da classe operária. Houve a homologação do Tratado de Versailles pelo parlamento brasileiro, no qual o governo se obrigou a regular as condições de trabalho (Vianna, 1989).

A Confederação Operária do Brasil (COB) foi criada em 1906. O período entre os anos de 1917 e 1920 foi marcado por inúmeras greves, principalmente em São Paulo e Rio de Janeiro (Fausto, 2002).

O governo de Artur de Bernardes (1922-1926) foi marcado por turbulências políticas e militares como a Semana de Arte Moderna, a Rebelião Tenentista (1922 e em 1924), Revolução Gaúcha (1923) e a Coluna Prestes (1925-1927). Artur de Bernardes reagiu a essas tribulações com medidas autoritárias, como o constante estado de sítio, restrições à liberdade de imprensa e a Reforma Constitucional de 1926 (Vicentino; Dorigo, 1998).

Entre 1926 e 1930, o Brasil foi governado por Washington Luís, que conseguiu restaurar a ordem política, mas com a quebra da bolsa de Nova York em 1929 houve queda de preços do café brasileiro. Os cafeicultores solicitaram auxílio ao governo, que rejeitou o pedido, gerando indisposição entre o governo e os produtores de café. As eleições de 1930 foram marcadas pela ruptura com a política do café-com-leite. Mineiros e gaúchos formaram a Aliança Liberal e lançaram a candidatura de Getúlio Vargas para presidente, e de João Pessoa, para vice, porém foram derrotados pelo candidato Júlio Prestes. Este resultado não foi aceito pela oposição, o que culminou na Revolução de 1930. No final de outubro de 1930, Washington Luís é deposto e Getúlio Vargas toma posse como presidente do Brasil na sede do Governo no Rio de Janeiro (Vicentino; Dorigo, 1998).

A partir da década de 1930, segundo Rodrigues (1968, p.346),"a ação conjunta de diversos fatores de ordem econômica, técnica, política e social acelerou a transformação da composição interna do proletariado". Em 19 de março de 1931, pelo Decreto no 19.770, foi regulamentada a sindicalização das classes patronais e operárias. Com base nesse Decreto, houve outras necessidades que foram detectadas e aprimoradas por meio do Decreto

\footnotetext{
4 Decreto no 979 - de 6 de janeiro de 1903, faculta aos profissionais da agricultura e indústrias rurais a organização de sindicatos para defesa de seus interesses (Brasil, 1903).
} 
no 24.694 de 1934, que abriu o direito de sindicalizar-se aos profissionais liberais e aos trabalhadores por conta própria (Moraes Filho, 1978).

Entretanto, a legislação do trabalho somente começou a ser cumprida quando passou a ter atrás de si órgãos fiscalizadores e aplicadores de penalidades, e assim foi criado o Ministério do Trabalho, Indústria e Comércio pelo Decreto no 19.443, de 26 de novembro de 1930, justamente com a finalidade de superintender a questão social, cuidando do amparo necessário aos trabalhadores nacionais (Moraes Filho, 1978).

O governo de Getúlio Vargas trouxe inúmeros benefícios para a classe trabalhadora. Em 1934, regulamentou-se o direito de férias e a Carteira de Trabalho. A indenização por dispensa e a estabilidade no emprego foi criada em 1935. Em 1941 foi criada a Justiça do Trabalho, e em 1943 foi promulgada a CLT, inspirada na "Carta Del Lavoro" da Itália fascista, e que sobrevive até os dias de hoje (Instituto Observatório Social, 2003).

A Consolidação das Leis do Trabalho foi instituída pelo presidente Getúlio Vargas, por meio do Decreto-lei n 5.452, de 1 de maio de 1943. A organização sindical foi fortemente influenciada pela legislação trabalhista em seu Título V - Da Organização Sindical, artigos 511 a 610. $\mathrm{NaCLT}$, Art. 511 aponta que:

\begin{abstract}
É licita a associação para fins de estudo, defesa $e$ coordenação dos seus interesses econômicos ou profissionais de todos os que, como empregadores, empregados, agentes ou trabalhadores autônomos, ou profissionais liberais, exerçam, respectivamente, a mesma atividade ou profissão ou atividades ou profissões similares ou conexas.

$\S 10 \mathrm{~A}$ solidariedade de interesses econômicos dos que empreendem atividades idênticas, similares ou conexas, constitui o vínculo social básico que se denomina categoria econômica (Daidone et al., 2001, p.120).
\end{abstract}

Após o término da 2a Grande Guerra Mundial, o Brasil passou por um período de desenvolvimento intenso por meio de uma política governamental que investiu fortemente na indústria e no comércio. A estrutura sindical que surgiu no Brasil durante o governo de Getúlio Vargas perdura até hoje, mas com a derrubada do Estado Novo (1945), é convocada a Assembleia Constituinte, que altera algumas leis e mantém a CLT. Nesse período surgiu o Movimento Unitário de Trabalhadores (MUT) com progra- ma de lutas reivindicatórias e políticas. OMUT deu origem à Confederação Geral dos Trabalhadores Brasileiros (CGTB), que teve seu funcionamento proibido em 1947, marcando a história da luta dos trabalhadores no Brasil. Em 1964, a ditadura intervém em mais de dois mil sindicatos, amparada pela CLT. No final da década de 1970, quando o movimento sindical sai para combater o regime militar e buscar os direitos dos trabalhadores, o governo recorre mais uma vez à CLT para cassar e prender os dirigentes grevistas, além de intervir nos sindicatos (Instituto Observatório Social, 2003)

De 1945 a 1964, houve a instalação de grandes empresas, ocasionando o aumento da mão-de-obra e do número de sindicalizados no país. Devido a essa demanda, a economia do país sofreu influência, houve necessidades trabalhistas relacionadas ao desemprego, inflação, salário, abastecimento, dentre outras gerando novas ações dos movimentos sindicais. De acordo com Martins (1989, p.77):

para tratar desses temas era necessário que houvesse uma integração maior entre os sindicatos, pois a estrutura vertical do sindicalismo brasileiro impedia a existência de órgãos de coordenação horizontal. Começaram a aparecer organizações paralelas. [...] Em 1955 foi organizado por um grupo de dirigentes sindicais, o Departamento Intersindical de Estatísticas e Estudos Sócio-Econômicos (DIEESE), órgão de assessoria técnico-econômica mantido por entidades sindicais de trabalhadores.

Após a queda de Vargas em 1945, os sindicatos adquiriram lentamente independência ante os organismos governamentais. No início da década de 1960, os sindicatos ganharam maior campo de atuação e o movimento operário ganhou mais liberdade. Rodrigues (1968, p.348) explica que "as lideranças não buscavam a remodelação da estrutura criada durante o Estado Novo, embora reivindicassem certa autonomia, perseguiam objetivos contraditórios". Buscavam a liberdade de ação e proteção para um sindicalismo que dificilmente poderia sustentar-se sem a garantia governamental, mostrando a debilidade da classe operária e, de outro lado, da natureza de suas aspirações e dos obstáculos que impedem sua consecução (Rodrigues, 1968).

Entre os anos de 1946 e 1964 o movimento sindical tentou criar organizações com estrutura horizontal e comando unificado, como o Pacto de Unidade e Ação 
(PUA), o Comando Geral de Greve (CGG), as Ligas Camponesas e o Comando Geral dos Trabalhadores (CGT), mas todas tiveram suas ações interrompidas com o Golpe Militar de 1964 (Departamento..., 2000).

O Regime Militar foi instalado em 1964 e perdurou por 21 anos e teve como presidentes os seguintes generais do exército: Humberto de Alencar Castello Branco (1964-1967), Artur da Costa e Silva (1967-1969), Emílio Garrastazu Medici (1969-1974), Ernesto Geisel (1974-1979) e João Batista Figueiredo (1979-1985) (Vicentino; Dorigo, 1998). O Regime Militar reprimiu os sindicatos ligados ao esquema populista, o número de sindicatos rurais aumentou e diversos sindicatos de profissionais autônomos surgiram e se fortaleceram (Fausto, 2002).

A partir da década de 1980, com as mudanças oriundas da globalização e das tecnologias, o mundo do trabalho foi afetado por processos de profissionalização e qualificação de mão-de-obra, cada vez mais exigente e excludente. Segundo Antunes (1996, p.133) "houve a redução do número de greves em vários países, porém aumentaram os casos de corporativismo, xenofobia, racismo na própria classe trabalhadora". No Brasil, nesse período ocorreu o inverso, houve grandes movimentos grevistas e avanços no sindicalismo rural. Em 1983 foi fundada a Central Única dos Trabalhadores (CUT). Com a CUT, avançou-se nas tentativas de organização dos locais de trabalho e na luta pela autonomia e liberdade dos sindicatos em relação ao Estado, há um aumento do número de sindicatos e de sindicalizados, configurando-se um quadro favorável para o sindicalismo no Brasil (Antunes, 1996). Foi após a criação da CUT que o sindicalismo brasileiro passou por uma fase importante, e a palavra de ordem deste momento histórico foi negociação.

A redemocratização aconteceu com a eleição indireta de Tancredo Neves em 1985, que faleceu antes de tomar posse. José Sarney assumiu e em fevereiro de 1986 anunciou o Plano Cruzado. A Assembleia Nacional Constituinte foi instaurada e em 5 de outubro de 1988 foi promulgada a nova Constituição (Fausto, 2002).

A década de 1990 foi marcada por crises no mundo do trabalho, a flexibilização da unidade fabril, desregulamentação dos direitos do trabalho, novos padrões de gestão, reengenharias, controle de qualidade, que afetaram a forma de ser do proletariado fabril, tradicional, atingindo os países capitalistas desenvolvidos e causando reflexos nos países do terceiro mundo, principalmente aqueles intermediários, dotados com significativo parque industrial, como o Brasil (Antunes, 1996).

As primeiras eleições diretas para presidente da República acontecem no ano de 1989. Fernando Collor de Mello é eleito e toma posse em 15 de março de 1990, o Plano Collor é divulgado um dia depois de sua posse. 0 plano consistia na reintrodução do Cruzeiro, congelamento de preços, gradual liberação e livre negociação de salários e confisco das contas correntes, poupanças e demais investimentos (Vicentino; Dorigo, 1998). Em 1991 é fundada a Central Força Sindical. O ano de 1992 é marcado pelo impeachment do presidente Fernando Collor de Mello, em seu lugar assumiu a presidência da República, Itamar Franco. Em 1994 é eleito o presidente Fernando Henrique Cardoso. Nesse período, uma grande greve foi realizada pelos petroleiros, aproximadamente sessenta grevistas foram demitidos e os sindicatos tiveram suas contas bloqueadas e seus bens penhorados. As negociações coletivas, depois do Plano Real (1995), procuram manter os direitos já conquistados. A Social Democracia Sindical (SDS) é formada em 1997 (Instituto Observatório Social, 2003).

O sindicalismo passou a viver uma crise de identidade com grande repercussão no movimento dos trabalhadores. Nesse período algumas transformações afetaram o mundo do trabalho como os processos de terceirização, as privatizações, a intelectualização do trabalho, a incorporação crescente das mulheres no mercado, entre outros fatores sociais, econômicos e políticos que impactaram nos movimentos sindicais, originando crises e debates no meio sindical.

O período compreendido entre os anos 2000 e 2010 foi marcado por greves nas Universidades e em algumas outras categorias. Há a realização do $1^{\circ}, 2^{\circ}$ e $3^{\circ}$ Fórum Social Mundial em Porto Alegre (RS). No segundo fórum participaram 4909 Organizações sindicais e Não-Governamentais (ONG), representando 123 países (Instituto Observatório Social, 2003).

O governo de Fernando Henrique Cardoso (1995-1998) foi marcado pela estabilidade da moeda, privatizações e desemprego, o que causou divergências entre os partidos políticos de oposição, os sindicatos e os funcionários das estatais e o Movimento dos Trabalhadores Rurais sem Terra (MST). Fernando Henrique Cardoso 
foi reeleito (1999-2002), período no qual o Real foi desvalorizado, o custo de vida subiu, a inflação aumentou, as privatizações continuaram e os investimentos diminuíram. Em agosto de 1999 ocorreu a "Passeata dos Cem Mil" realizada pelo MST, sindicatos, União Nacional dos Estudantes e partidos políticos de oposição (Ordoñez; Quevedo, 2005). Durante o Governo de Fernando Henrique Cardoso foi criado e implantado o novo plano de estabilização econômica, a Lei n. 8.880, de 27 de maio de 1994, que proibiu reajustes automáticos nos salários, deixando de haver um patamar mínimo de correção salarial oficial que servisse de base para negociação com empresários e com o próprio governo, o que abalou a capacidade de pressão e a barganha sindical foi afetada pela política econômica e pelas reformas liberalizantes (Oliveira, 2003).

Percebe-se que o sindicalismo hoje é diferente daquele vivenciado no auge das décadas de 1970 e 1980, cuja postura era socialista e anticapitalista. As tendências econômicas, políticas e ideológicas acentuaram as mudanças causadas pela automação e desproletarização de importantes contingentes operários. Frente à emergência de um sindicalismo neoliberal, a força sindical, com forte dimensão política e ideológica, vem mudando em busca da nova direita, da preservação da ordem, da sintonia com o capital globalizado (Antunes, 1996).

Nas eleições realizadas em 2002, ocorreu a eleição de Luís Inácio da Silva, popularmente conhecido como Lula. A retomada do crescimento aconteceu a partir de 2004, com a expansão da economia internacional, da estabilidade de inflação, do aumento do crédito popular e do salário-mínimo, assim, o Governo Lula obteve números bastante favoráveis em relação ao crescimento do emprego, dos rendimentos e do consumo dos trabalhadores. O Governo convocou o Fórum Nacional do Trabalho, para promover o diálogo e a negociação com os sindicatos e classes trabalhistas. Com a reeleição de Lula em 2006, a reforma sindical voltou à tona, mas quando retornou ao debate nacional voltou de forma fragmentada, o que não trouxe alterações profundas ao modelo sindical (Rodrigues et al., 2008).

\section{Funcionamento dos sindicatos no Brasil}

Entre os anos de 1920 e 1930 havia aproximadamente 131 sindicatos registrados, dos quais 62 na Capital e 69 no interior. As primeiras categorias profissionais a se organizarem em associações e sindicatos foram de trabaIhadores da indústria de força e luz elétrica, cal e cimento, produtos químicos, artefatos de borracha, papel, frigoríficos e laticínios (Simão, 1981).

O artigo 522 da CLT afirma que "a administração do sindicato será exercida por uma diretoria constituída, no máximo, de 7 (sete) e, no mínimo, de três membros e de um conselho fiscal composto de três membros, eleitos esses órgãos pela assembleia geral" (Daidone et al., 2002, p.123). Em relação aos empregados do sindicato, a CLT em seu artigo 526 afirma que os mesmos serão nomeados pela diretoria respectiva ad referendum da assembleia geral, não podendo recair tal nomeação nos que estiverem nas condições previstas nos itens II, IV, V, VI, VII e VIII do artigo 530 e, na hipótese de o nomeado haver sido dirigente sindical, também nas do item I do mesmo artigo (Daidone et al., 2002).

A estrutura sindical consiste em um sistema confederativo, ou seja, há os sindicatos na base, as federações, estão no nível intermediário, e as confederações estão no nível superior. Isso pode ser verificado na Seção V da CLT que aborda o tema "Das Associações Sindicais de Grau Superior", segundo o artigo 533 "constituem associações sindicais de grau superior as federações e confederações organizadas nos termos desta Lei" (Daidone et al., 2002, p.128). O artigo 534 aponta que "é facultado aos Sindicatos, quando em número não inferior a 5 (cinco), desde que representem a maioria absoluta de um grupo de atividades ou de profissões idênticas, similares ou conexas, organizarem-se em federação" (Daidone et al., 2002, p.128). O artigo 535 aborda a organização e nomenclatura das confederações e afirma que as mesmas terão sede na Capital da República (Daidone et al., 2002).

Os sindicatos são mantidos por meio das seguintes fontes:

Contribuição compulsória - o chamado Imposto Sindical - que é um desconto direto na folha de pagamento no valor equivalente a um dia de trabalho por ano. Sua existência é uma das razões que explica o alto número de sindicatos no Brasil. Hoje, segundo o Ministério do Trabalho, são cerca de 15 mil sindicatos, inclusive patronais. Em média, são criados aproximadamente 500 sindicatos por ano. 
Mensalidade - é uma contribuição mensal do associado. O valor geralmente é instituído em assembleia e corresponde a uma percentagem do salário do trabalhador. É uma contribuição voluntária.

Taxa assistencial - é um valor estipulado no processo de negociação coletiva das entidades sindicais. É definido pela própria categoria, em assembleia. A taxa assistencial foi criada com a finalidade de manter as atividades sociais do sindicato em um período em que não podia exercer a sua verdadeira função. Atualmente, muitos sindicatos estão convertendo, na prática em uma taxa negocial, para financiar a campanha salarial, as mobilizações sindicais ou incrementar o patrimônio da entidade sindical.

Taxa confederativa - é uma taxa criada da Constituição de 88, que deveria substituir o imposto sindical, para a manutenção do sistema confederativo. A diferença é que o seu valor e o destino dos recursos arrecadados são definidos em assembleia dos trabalhadores (Instituto Observatório Social, 2003, p.20, grifos do autor).

Verifica-se que a organização e estruturação dos sindicatos e a aplicação da legislação fez com que os mesmos crescessem de maneira significativa nas últimas duas décadas. A quantidade de sindicatos e do número de associados tem aumentado consideravelmente. Segundo estudos realizados pelo Instituto Brasileiro de Geografia e Estatística - IBGE (1992) e pelo Departamento Intersindical de Estatística e Estudos Socioeconômicos (2008), o número de sindicatos em 1987 era de 9118 com 16326538 associados, já em 2001 havia 11354 sindicatos com 19528311 associados.

Os trabalhadores têm ampliado sua atuação junto às classes sindicais, os setores mais sindicalizados da economia são: Agrícola com 4450 788, Indústria com 3126723 , Indústria de transformação com 2846316 , Educação, saúde e serviços sociais com 2464 039, Comércio e reparação com 1903 674, Outras atividades com 1581778 e Transporte, armazenagem e comunicação com 1040 697, já os demais setores possuem números abaixo de um milhão de associados (Departamento Intersindical..., 2008).

Estudos realizados pelo IBGE em 1992 e pelo DIEESE em 2008 permitem relacionar informações sobre o aumento do número de sindicatos de profissionais liberais, observa-se que no ano de 1987 havia 343 sindi- catos, enquanto em 2001 havia 483 sindicatos, o que corresponde a um aumento superior a $40 \%$.

Apesar do crescimento verificado, observa-se que:

O trabalho industrial tornou-se minoritário, superado pelo comércio e pelos serviços. A relação subordinante - ainda numericamente dominante em termos universais - passa por enormes alterações e vê múltiplas práticas ocupacionais crescendo ao seu derredor: o trabalho eventual, o autônomo, o casual, o móvel, o terceirizado, a distância, o domiciliar, o a tempo parcial etc. (Chiarelli, 2005, p.310).

Os sindicatos devem se adequar as novas necessidades do cidadão e do trabalhador. Chiarelli (2005, p.314) afirma que "novas regras, comportamentos e condutas precisam ser criados e socialmente incorporados e cumpridos, oferecendo um 'pacote' (variável e adaptável) de proteção a essa maioria" de novos modelos de trabalhadores que não se adequam aos formatos anteriormente conhecidos, mas que devem usufruir das mesmas vantagens dos demais.

Essas alterações devem acontecer em todos os níveis e abranger todas as categorias de profissionais, como os sindicatos de Bibliotecários existentes em todo o Brasil, os quais serão abordados a seguir.

\section{Sindicatos de bibliotecários no Brasil}

No Brasil, a Biblioteconomia é uma profissão regulamentada pela n 4.084, de 30 de junho de 1962 que dispõe sobre seu exercício. O Decreto n 56.725, de 16 de agosto de 1965 destaca em seu Artigo $2^{\circ}$ que a designação profissional do bibliotecário foi incluída no quadro das profissões liberais da CLT. A Federação Brasileira de Associações de Bibliotecários, Cientistas da Informação e Instituições (2010), fundada em julho de 1959, é uma das principais forças de representação da classe bibliotecária junto com o Conselho Federal de Biblioteconomia, criado em dezembro de 1965.

Visando a defesa e o incentivo do desenvolvimento da profissão no país, a FEBAB é uma sociedade civil, sem fins lucrativos e reúne dezessete associações de Biblioteconomia no país, contemplando 16 Estados e o Distrito Federal (Federação Brasileira..., 2010).

O Conselho Federal de Biblioteconomia foi previsto na Lei no 4.084 de 1962, porém, foi oficialmente 
instalado somente em março de 1966 com a posse dos membros da primeira gestão. A partir da regulamentação da profissão, foram criados nos estados, os Conselhos Regionais que são subordinados ao CFB e tem por objetivo fiscalizar o exercício da profissão de bibliotecário e contribuir para o aprimoramento da área e seus profissionais. Atualmente, existem quinze conselhos espalhados por todo país. Os Conselhos Regionais exercem ações administrativas, normativas, supervisoras e disciplinares, tendo ainda por finalidades gerais: zelar pelo bom conceito da profissão, orientar e defender o livre exercício da profissão, julgar infrações à Lei e à Ética, servir como órgão consultivo do Governo, no que se refere aos interesses dos bibliotecários. Também é sua atribuição a organização e manutenção de cadastros de profissionais registrados, de escolas de biblioteconomia e de bibliotecas e centros de documentação (Conselho Federal de Biblioteconomia, 2010).

A FEBAB, as associações e os conselhos regionais visam à representação da classe por meio da promoção de eventos, cursos de capacitação continuada e desenvolvimento profissional dos bibliotecários, fiscalização da profissão, entre outros. Entretanto, até a década de 1980, não existia no campo trabalhista uma representação coletiva legal da profissão ou um órgão de classe que tivesse poderes legítimos para defender os interesses dos bibliotecários frente às autoridades administrativas e judiciárias como acordos coletivos, estabelecimento de piso salarial, jornada de trabalho e demais vantagens previstas ou não na CLT.

De acordo com o Boletim Informativo do Sindicato dos Bibliotecários no Estado do Rio de Janeiro (2005), em meados de 1970, foi criado o primeiro sindicato de bibliotecários no Brasil, localizado no estado da Bahia. O sindicato surgiu a partir da mobilização de Antônio Gabriel, então presidente da FEBAB, que viajou pelo Brasil para criar associações profissionais. A criação de associações profissionais era exigência do regime militar para criação de sindicatos. Após conseguir registro no Ministério do Trabalho, a Associação foi transformada em Sindicato. Entre 1986/1987 a documentação do Sindicato ficou retida em Brasília e só foi devolvida em 1990. Com evento realizado em Salvador em 1991 conseguiram comprar equipamentos (fax e computador) e nesse mesmo ano promoveram mais de 15 cursos. Em 1994, o Sindicato foi transformado em Associação que funcionou até 1997. Nesse período houve muitos problemas administrativos e de ordem financeira que perduraram até 2005, culminando na não liberação da carta sindical. Foi convocada assembleia geral com a finalidade de adequar o estatuto ao novo Código Civil, mas não houve quorum suficiente. Em 2005, passaram a arrecadar fundos para que a nova diretoria, formada por alunos, pudesse assumir o sindicato, porém não houve sucesso (Boletim..., 2005). Neilton dos Santos Barreto, presidente eleito em 2005 para o Sindicato de Bibliotecários da Bahia, relata que atualmente o sindicato enfrenta dificuldades e está desativado devido à falta de consciência profissional dos bibliotecários baianos conforme entrevista (Barreto, 2011).

Recentemente, foram registradas mensagens por meio de listas de discussão da área de Biblioteconomia sobre um convite para reuniões para tentar reestruturar novamente o sindicato de bibliotecários da Bahia (Alencar, 2011).

O Sindicato dos Bibliotecários no Estado de São Paulo nasceu em 1985, quando o movimento sindical no Brasil começava a tomar força. Um grupo de bibliotecários que na época dirigia a Associação Profissional dos Bibliotecários do Estado de São Paulo (APBESP), encaminhou ao Ministério do Trabalho proposta para transformação da Associação, que fora criada em 1977, em Sindicato (Sindicato dos Bibliotecários no Estado de São Paulo, 2008a).

O Sindicato dos Bibliotecários no Estado de São Paulo (SINBIESP) é uma organização que representa legalmente os bibliotecários atuantes naquele estado, tendo como principais objetivos:

Defender a categoria profissional liberal dos Bibliotecários, composta de profissionais autônomos, servidores públicos, trabalhadores assalariados e aposentados; propor e participar de negociações coletivas; instaurar dissídios coletivos de trabalho; amparar a classe através de serviços de assessoria jurídicas e promover apoio às iniciativas que priorizem a educação, o desenvolvimento e a valorização do profissional no mercado de trabalho. Direcionando-se pela melhoria contínua dos processos e serviços, o SinBiesp busca cada vez mais, estreitar o relacionamento com a classe Bibliotecária, disponibilizando diferentes canais de comunicação visando manter os profissionais informados quanto às ocorrências relevantes, bem como, orientá-los quanto aos 
diferentes aspectos do mercado de trabalho, objetivando sua valorização e embasamento legal para negociações salariais junto aos empregadores (Sindicato dos Bibliotecários no Estado de São Paulo, 2008b).

De acordo com Sindicato dos Bibliotecários no Estado de São Paulo (2008a) a primeira eleição ocorreu em novembro de 1985, com chapa única liderada pelo bibliotecário José Domingos de Brito. A fixação do piso salarial e de uma tabela de honorários, a defesa das prerrogativas profissionais e a sindicalização do funcionalismo público eram algumas das bandeiras da primeira diretoria do Sindicato. Durante dez anos, o sindicato funcionou dentro da própria Associação Paulista de Bibliotecários (Sindicato dos Bibliotecários no Estado de São Paulo, 2008a). Durante esse tempo, houve tentativas para a convenção coletiva de trabalho da categoria, lutas pelo piso salarial, entre outros avanços para a categoria profissional de São Paulo, por meio de um trabalho árduo, na época presidida pela bibliotecária Vera Stefanov.

Somente em 1994, houve a primeira Convenção Coletiva de Trabalho dos Bibliotecários, fortalecendo as ações do SinBiesp no reconhecimento da organização sindical da categoria por outros sindicatos de trabalhadores. Foi nesse ano que o Sindicato adquiriu a primeira sede e iniciaram-se estudos para a criação de um estatuto. Na Assembleia da categoria ocorrida em 1997, o novo estatuto do Sindicato foi aprovado. O desenvolvimento da estrutura de atendimento aos associados na nova sede representou, a partir de 1998, a intensificação dos trabalhos nas áreas de assessoria jurídica, bolsa de empregos e ampliação de convênios (Sindicato dos Bibliotecários no Estado de São Paulo, 2008a).

No Paraná, com a missão de "representar e defender os bibliotecários, buscando a democratização do saber e o desenvolvimento humano", o Sindicato de Bibliotecários (SINDIB/PR) foi constituído em 1988, como Associação Profissional, por imposição da legislação da época. Foi reconhecido como entidade sindical pelo Ministério do Trabalho somente em 27 de agosto de 1991. Desde sua criação, o SINDIB/PR teve 297 filiados, mas em 1998 havia apenas sessenta filiados, o que causou problemas na sua manutenção. Em 2005 eram 186 filiados, mas apenas oitenta saldaram as anuidades, dificultando as ações. Foram realizados alguns cursos em Curitiba, que contaram com a participação de bibliotecários do interior. O mesmo possui um serviço de bolsa de empregos e luta pelo estabelecimento pleno do piso salarial e a resistência dos sindicatos patronais, principalmente o das escolas (Memória..., 2005).

Atualmente SINDIB/PR disponibiliza em sua homepage (http://www.sindib.pr.gov.br/) alguns serviços como banco de empregos, organização e divulgação de cursos, tabela salarial de serviços bibliotecários, Jornal do Bibliotecário Paranaense (InformAção), entre outros. Tem vigente a Convenção Coletiva de Trabalho de 2010 a 2011 e atualmente possui 202 filiados, porém apenas 50\% desses profissionais estão ativos.

Conforme o Sindicato dos Bibliotecários no Estado do Rio de Janeiro (2011), no Estado do Rio de Janeiro, o sindicato de bibliotecários teve origem na Associação Profissional dos Bibliotecários do Rio de Janeiro (APB-RJ), aprovado em assembleia em 15 de agosto de 1989 tem por objetivos:

Defender os direitos e interesses coletivos ou individuais da categoria; representar judicial ou extrajudicialmente os interesses coletivos e/ou individuais da categoria, inclusive funcionando como substituto processual da categoria; promover e participar obrigatoriamente das negociações coletivas de trabalho com vistas à celebração de convenções e acordos coletivos com os sindicatos patronais e/ou entidades públicas ou privadas; propiciar a organização da categoria promovendo a eleição de representantes e delegados sindicais; promover a solidariedade entre seus representados e destes com as demais categorias profissionais; promover o desenvolvimento cultural e profissional dos representados; prestar assistência a seus associados, na forma que a Assembleia Geral decidir; colaborar, como órgão técnico e consultivo, com o poder público e o setor privado, no estudo e solução dos problemas que se relacionem com a categoria (Sindicato dos Bibliotecários no Estado do Rio de Janeiro, 2010).

Segundo informativo sobre a contribuição sindical para 2011, disponível no portal do SINDIB/RJ (http://www. sindib.pr.gov.br/), aproximadamente trezentos profissionais contribuem com o sindicato. José Renato Lopes de Oliveira, presidente do Sindicato dos Bibliotecários do Rio de Janeiro em 2005, relatou que assumiu em junho de 2003 juntamente com membros oriundos do movimento estudantil. Explicou que no Rio de Janeiro a categoria não tem prestigiado o sindicato, gerando falta de 
recursos financeiros. Comentou que após várias campanhas de filiação conseguiram chegar a quatrocentos filiados, mas poucos realmente pagam a contribuição sindical. Seu trabalho teve como objetivo recuperar o prestígio do Sindicato junto à classe e fortalecê-lo financeiramente (Memória..., 2005).

Atualmente, o SINDIB/RJ edita o boletim eletrônico, promove viagens turísticas, atua junto às universidades divulgando o trabalho desenvolvido e mantém parceria com o CRB. A diretoria participa de reuniões com outros sindicatos para se tornar conhecida. De acordo com o Boletim... (2005), Oliveira cita que os sindicatos precisam fazer política para serem fortes e se preocupar com a saúde do trabalhador além de continuar na luta por um piso salarial condizente com a profissão e com melhores condições de trabalho.

Em Santa Catarina, ocorrem discussões sobre a possível criação de um sindicato desde a década de 1980, porém, somente em 2008, durante o XXVII Painel Biblioteconomia de Santa Catarina (http://painel2008.acbsc. org.br/), evento anual promovido pela Associação Catarinense de Bibliotecários, cuja temática principal foi"Espaço e Atuação Política do Bibliotecário", coordenado pela bibliotecária Daniela Oliveira Spudeit, é que aconteceram vários debates e mesas-redondas, sendo que a sindicalização da profissão foi pauta de várias falas durante a programação.

Entretanto, somente na 29a edição do Painel Biblioteconomia de Santa Catarina (http://www.painel2010. acbsc.org.br/), coordenado pela bibliotecária Miriam C.M. Matos, é que houve um debate mais direcionado e efetivo em relação à criação de um sindicato de bibliotecários no estado de Santa Catarina, pois ocorreu uma reunião entre associações, sindicatos e conselhos sobre os desafios e as perspectivas da organização dos bibliotecários. Esse evento contou com a participação de profissionais de vários estados brasileiros e do Distrito Federal, inclusive com representantes de outras associações, sindicatos, conselhos regionais e do Conselho Federal de Biblioteconomia, presidido pela bibliotecária Nêmora Arlindo Rodrigues, que também esteve presente no evento.

Após o evento, em outubro de 2010, foi criada uma comissão nomeada "Pró-SindBiblio/SC", coordenada pela bibliotecária Miriam C. M. Matos, que fez os encaminhamentos necessários para a formalização do reconhecimento da entidade junto ao Ministério do Trabalho e Emprego para a concessão da carta sindical.
Oficialmente, o SindBiblio/SC foi fundado na Assembleia Geral da categoria realizada na Assembleia Legislativa de Santa Catarina em 3 de dezembro de 2010, porém ainda prossegue em seu processo de estruturação, possui o registro em cartório e CNPJ, atualmente está estruturando um instrumento de coleta de dados para mapeamento dos bibliotecários no Estado, quem são, quantos são, onde atuam, entre outras informações.

Recentemente, em meados de julho de 2011, iniciou-se um trabalho de elaboração de materiais de divulgação do SindBiblio/SC, carteirinha para sindicalizados, criação de uma política de convênios e captação dos mesmos para uma posterior agenda de visitas às empresas e instituições. Entretanto, a entidade aguarda o Registro Sindical, pois foi dado entrada no pedido na Superintendência Regional do Trabalho e Emprego (SRTE/SC) que, após análise, encaminhou o processo ao Ministério do Trabalho e Emprego, em Brasília em fevereiro de 2011.

Segundo o blog do SindBiblio/SC (disponível em http://sindibibliosc.blogspot.com) durante o ano de 2011, enquanto aguarda a expedição da carta sindical, a diretoria do Sindicato buscará solidificar parcerias, promoverá atividades de debate para dirimir dúvidas e buscará apoio e sugestões que apontarão os caminhos a serem tomados pelo SindBiblio/SC visando ampliar a organização e fortalecimento da categoria profissional dos bibliotecários.

No decorrer do processo de estruturação, todas as informações sobre a comissão e a criação do sindicato foram repassadas e debatidas amplamente na Lista de Discussão da Associação Catarinense de Bibliotecários (ACB) e por meio do Conselho Regional de Biblioteconomia (CRB) da 14a região - Santa Catarina. Posteriormente foi criado um blog (http://sindbibliosc.blogspot.com/) e o twitter (http://twitter.com/SindbiblioSC) para reunir todas as informações sobre o processo de criação do Sindicato de Bibliotecários de Santa Catarina (SindBiblio/SC).

Além dos estados já citados, havia sindicatos de bibliotecários em Minas Gerais e no Maranhão, porém, atualmente, estão desativados conforme será relatado a seguir.

O Sindicato de Bibliotecários de Minas Gerais (SIBMG) iniciou na década de 1980, porém, em seguida, foi desativado. Registros confirmam que somente em 2004 com uma comissão de bibliotecários insatisfeitos com seus salários, o sindicato foi novamente reestruturado. Em fevereiro de 2005, a primeira diretoria toma posse 
e funda o sindicato com a presença do presidente do SINDIB/RJ e do Conselho Regional de Biblioteconomia de Minas Gerais, porém, após 2008, não houve continuidade das ações (Memória..., 2005).

Padilha (2011, online), membro da Associação de Bibliotecários de Minas Gerais, relata que,

o SIBMG foi fundado em 2005, mas não houve continuidade das ações. O mandato da diretoria venceu em 2008 e quando tentamos renovar, o cartório não foi aceitou pelo fato do mandato ter acabado há mais tempo. No cartório fomos informados de que teríamos que recorrer à Justiça e isso foi feito, entretanto, não obtivemos sucesso e fomos orientados que isso era de responsabilidade do cartório. No decorrer desse processo passaram-se alguns meses e o grupo que estava tentando reanimar o sindicato acabou desanimando. Desde então, o SIBMG está parado e atualmente faço parte da Associação de Bibliotecários de Minas Gerais que está também se reestruturando.

Para Tunes (2011), membro da antiga diretoria do SIBMG, que tentou regularizar a situação do sindicato, relata que "apesar de aprovado em assembleia, o SIBMG ainda não foi reconhecido como uma entidade sindical, não conseguimos o registro junto ao MTE". Assim, como outros sindicatos da área, essas dificuldades na estruturação, legalização e composição de chapas e plano de desenvolvimento da entidade, também foi a justificativa da extinção de outros sindicatos.

O Sindicato de Bibliotecários do Maranhão (SINDIB/MA) foi fundado em novembro de 2003 pela necessidade de um órgão que representasse e lutasse pela categoria. Inicialmente se instalou em uma sede provisória junto ao Sindicato dos Bancários. Na época da criação, buscou-se o apoio da Universidade, mas nenhum professor compareceu à assembleia e assim houve dificuldade de trabalhar com os alunos e mostrar o apoio que a instituição pode dar aos futuros profissionais (Memória..., 2005). Em 2009, houve tentativas para reestruturar o sindicato e renovar a documentação, porém já havia expirado o prazo e por problemas judiciais ainda não foi oficialmente ativado.

Em 2010, mesmo ano em que houve a iniciativa catarinense para criação do Sindicato de Bibliotecários do Estado de Santa Catarina, localizou-se a iniciativa da
Comissão Pró-fundação do Sindicato dos Profissionais Liberais Bibliotecários dos Estados da Pará, Amapá e Tocantins (SIBIB) que ainda estão tentando se estruturar.

Atualmente, existem oito sindicatos de bibliotecários no país, dois situados na região Sul (Paraná e Santa Catarina), três na região Sudeste (São Paulo, Minas Gerais, Rio de Janeiro), dois, na região Nordeste (Bahia e Maranhão) e um na região Norte que abarca os estados do Pará, Amapá e Tocantins. Entretanto, esta pesquisa mostrou que, em 2011, apenas quatro sindicatos estão atuantes, que são: Rio de Janeiro, Paraná, São Paulo e Santa Catarina, sendo que este último está em fase de estruturação. Nos Estados da Bahia, de acordo com Barreto (2011) e em Minas Gerais, conforme Padilha (2011) e Tunes (2011), os sindicatos estão desativados, porém foram registradas em março de 2011 algumas mensagens por meio de listas de discussão da área de Biblioteconomia sobre um convite para reuniões para tentar reestruturar os sindicatos de bibliotecários novamente (Alencar, 2011).

Em 2005, aconteceu o I Encontro Nacional de Sindicatos, durante o XXI Congresso Brasileiro de Biblioteconomia, no qual se discutiu a criação da Federação de Sindicatos, visando unir as forças e reivindicar melhoria para a classe dos bibliotecários, pois a Federação poderá negociar benefícios para a categoria em nível nacional caso a reforma sindical seja aprovada. Durante esse evento, foi sugerido também que os sindicatos estudassem a implantação de estatuto único e a criação de boletim para divulgação dos sindicatos para a categoria (Memória..., 2005).

Em 2006, aconteceu o II Encontro Nacional de Sindicatos de Bibliotecários, em Salvador, durante o XIV Seminário Nacional de Bibliotecas Universitárias (http:// www.snbu2006.ufba.br/). Durante o XXIII Congresso Brasileiro de Biblioteconomia, Documentação e Ciência da Informação (CBBD) (http://www.febab.org.br/XXIII_CBBD/), 2009, houve novo encontro dos Sindicatos de Bibliotecários no qual seriam discutidos a formação de sindicatos dos profissionais bibliotecários e o mercado de trabalho.

A Associação Catarinense de Bibliotecários também tem aberto espaços nos eventos para promover a discussão sobre a atual situação e as principais dificuldades encontradas pelas entidades de classe, principalmente sindicatos e associações, que dependem exclusi- 
vamente da iniciativa voluntária de profissionais bibliotecários para se manterem.

Algumas estratégias e grupos de trabalho se formam nestes eventos, entretanto, os relatórios das últimas edições do Painel Biblioteconomia em Santa Catarina e atas de reuniões das associações e dos Grupos Especializados em diferentes áreas de atuação da Biblioteconomia mostram que poucas iniciativas têm obtido sucesso.

Entretanto, avanços têm ocorrido devido à forte atuação do Conselho Federal de Biblioteconomia, uma delas foi a vitória com a aprovação da Lei no 12.244, aprovada em maio de 2010 pelo presidente Luiz Inácio Lula da Silva, que dispõe sobre a universalização das bibliotecas nas instituições de ensino do País. Segundo a lei, as instituições de ensino públicas e privadas de todos os sistemas de ensino do País contarão com bibliotecas e as escolas têm um prazo máximo de dez anos para se adaptar a esta lei, respeitada a profissão de Bibliotecário, disciplinada pelas Leis no 4 .084, de 30 de junho de 1962, e 9.674, de 25 de junho de 1998 (Brasil, 2010).

A promulgação da Lei n¹2.244 em maio de 2010 representa uma das maiores conquistas da Biblioteconomia brasileira, considerando o alcance que as medidas ali previstas acarretarão para os beneficiários em todos os níveis e em todos os setores. Visando padronizar as medidas para implantar a lei, o Sistema CFB/CRB conta com o apoio do Grupo de Pesquisa em Bibliotecas Escolares (GEBE), vinculado à Universidade Federal de Minas Gerais (UFMG), que desenvolveu minuciosa investigação e de posse desses padrões, serão retomadas as tratativas com o MEC e sistemas estaduais e municipais de educação em todo o país para que sejam implantados conforme prevê a legislação (Conselho Federal de Biblioteconomia, 2011, online).

Além disso, de acordo com Conselho Federal de Biblioteconomia (2011, online), entre outras ações que estão sendo realizadas e acompanhadas pelo Conselho Federal de Biblioteconomia, pode-se citar as principais que buscam também valorizar a atuação dos bibliotecários nas políticas públicas:

- Participação ativa da bibliotecária Nêmora Rodrigues, Presidente do CFB e integrante do Colegiado Setorial do Livro, Leitura e Literatura (CSLLL), órgão vinculado ao Ministério da Cultura (MinC), na audiência pública para discutir as questões ligadas às propostas de estru- turação, institucionalização e implementação do Sistema Nacional de Cultura (SNC).

- Censo sobre as bibliotecas públicas brasileiras - o Ministério da Cultura (MinC) contratou a Fundação Getúlio Vargas para fazer uma pesquisa sobre a situação das bibliotecas públicas, apresentou resultados plenamente conhecidos pelo Sistema CFB/CRB. Com estes dados, será possível traçar outras estratégias para reverter o desequilíbrio regional e suprir as deficiências existentes, no acervo, nos recursos humanos, nas estruturas e na acessibilidade dessas bibliotecas.

- Censo sobre os bibliotecários brasileiros - a inexistência de dados consolidados sobre o bibliotecário brasileiro levou o Sistema CFB/CRB a prospectar e implantar um cadastramento profissional, na expectativa de compreender o perfil do grupo registrado pelo organismo que deve promover a proteção da coletividade contra os leigos inabilitados, como também dos habilitados sem ética.

- Oferta do curso de bacharelado em Biblioteconomia na modalidade a distância: A necessidade de formar um maior contingente de bibliotecários no país sem abrir mão da qualidade, em vista da implantação de diversos projetos nacionais que envolvem a contratação de profissionais, motivou o Sistema CFB/CRB a constituir uma parceria com a Coordenação de Aperfeiçoamento de Pessoal de Nível Superior (CAPES), por meio da Universidade Aberta do Brasil (UAB) para a oferta do curso de bacharelado em Biblioteconomia na modalidade a distância. A principal justificativa se deve à aprovação da Lei 12.244, que determinou a contratação de 175 mil bibliotecários até 2020.

Entretanto, todas essas ações lideradas pelo Conselho Federal de Biblioteconomia em parcerias com universidades e outros órgãos vem para propiciar maiores oportunidades de trabalho e de atuação junto às escolas e instituições públicas e particulares. Porém, cabe aos sindicatos de bibliotecários a defesa dos interesses desses profissionais, já que nem sempre os salários pagos são justos e as condições de trabalho nem sempre são respeitadas. E essa luta pelas melhores condições de trabalho cabe aos sindicatos, ou seja, o Conselho e as Associações têm feito sua parte, para promover a visibilidade da profissão, bem como a capacitação desses 
profissionais em cursos e eventos, e agora cabe aos sindicatos fazerem sua parte.

Periodicamente, as diretorias desses sindicatos se reúnem para debater sobre reformas sindicais, representatividade da profissão, entre outros assuntos. Os sindicatos de bibliotecários têm ampliado sua atuação e buscado melhores condições de trabalho para seus profissionais, porém, há muito por se fazer para que os direitos dos trabalhadores sejam atingidos e respeitados pelos empregadores.

\section{Considerações Finais}

Cada vez mais o mundo do trabalho exige a ampliação das habilidades e competências para que os profissionais obtenham sucesso em sua carreira. Na sociedade atual, é crescente a necessidade de organização e representação das profissões por meio das entidades e órgãos de classe, pois essas instituições agrupam os profissionais visando a coletividade e a defesa dos interesses da categoria e dos profissionais que a compõem, além disso, favorece a valorização, o reconhecimento, e, principalmente, o fortalecimento da profissão na sociedade.

Aos bibliotecários essa necessidade é evidenciada, pois a sociedade é baseada na informação e no conhecimento. O surgimento de novas técnicas de produção, difusão e gestão das informações implica em atitudes e perfis diferenciados influenciando a forma de atuação dos bibliotecários, já que a mediação passa a se destacar no cotidiano do profissional da informação.

Frente a esses desafios tecnológicos e mudanças sociais, o papel do bibliotecário fica cada vez mais evidente nos processos de comunicação, transferência da informação e de mediação na construção de novos conhecimentos, impactando na percepção sobre a profissão. Esses fatores exigem do bibliotecário uma postura mais crítica e reflexiva sobre sua atuação, que vai ao encontro do propósito dos sindicatos profissionais, que buscam a defesa dos direitos dos profissionais perante a sociedade, o Estado e o mercado.

Ao iniciar os estudos para implantação de um sindicato de bibliotecários no Estado de Santa Catarina, percebeu-se a reduzida quantidade de publicações acadêmico-científicas a esse respeito na literatura científica.
Perante estas dificuldades, percebeu-se a relevância de resgatar estes dados sobre a história, criação, desenvolvimento e atuação dos sindicatos de bibliotecários no Brasil, sendo este o objetivo alcançado pelo presente artigo, buscando que este traga contribuições relevantes para uma discussão acadêmico-científica acerca da importância desses sindicatos para a integração destes profissionais e valorização da profissão pela sociedade.

Percebe-se que o grande problema que infringe as gestões dos sindicatos, associações e conselhos de Biblioteconomia é a falta de pessoas que sejam comprometidas e possam se dedicar pela luta e pela defesa dos bibliotecários no Brasil. Para isso, é importante mudar o discurso dos próprios profissionais, é necessário fazer um trabalho de base pelas entidades de classe para conscientizar os bibliotecários atuantes e principalmente os estudantes de Biblioteconomia. As novas gerações de profissionais precisam ser mais engajadas socialmente na profissão e torna-se necessário traçar estratégias para sensibilização dos profissionais para que atuem ativamente em prol da profissão, ao invés de apenas reclamar das anuidades cobradas pelas entidades, já que todas têm pessoas voluntárias que estão à frente desses órgãos tentando fazer algo pela profissão.

Atualmente, existem três sindicatos de bibliotecários ativos que estão situados no Estado de São Paulo, Rio de Janeiro e no Paraná, os demais porém, estão funcionando em precárias condições por falta de profissionais comprometidos com esta luta. Além destes, existe um sindicato no Estado de Santa Catarina, em processo de estruturação. Por meio de uma pesquisa bibliográfica e exploratória, conseguiu-se mapear e analisar a situação e a evolução dos sindicatos de bibliotecários atualmente. Percebem-se as dificuldades para estruturação e manutenção destes órgãos no país e a necessidade da participação ativa dos profissionais bibliotecários dentro dos sindicatos para o fortalecimento de sua própria profissão.

Os sindicatos de bibliotecários possuem a função de defender os direitos trabalhistas, representar a categoria profissional junto ao Judiciário, governos, empresas privadas e possuem o poder de celebrar Acordos e Convenções Coletivas de Trabalho. Porém, para a consolidação dessas entidades, para o fortalecimento da identidade dos bibliotecários enquanto categoria profissional exige-se a conscientização da sociedade e a coesão e participação ativa dos profissionais bibliotecários. 
ALENCAR, A. Reunião do Sindicato dos Bibliotecários do Estado da Bahia. [Lista de discussão Bibliotecários]. Disponível em: <http://www.bibliotecarios.com.br>. Acesso em: 23 mar. 2011.

ANTUNES, R. Mundo do trabalho e sindicatos na era da reestruturação produtiva: impasses e desafios do novo sindicalismo brasileiro. Transinformação, v.8, n.3, p.130-137, 1996.

BARRETO, N.S. Sindicato Bahia. [mensagem pessoal]. Mensagem recebida por<neilto@sei.ba.gov.br> em 15 jan. 2011.

BRASIL. Decreto no 979, de 6 de janeiro de 1903. Rio de Janeiro: [s.n.], 1903. Disponível em: <http://www6.senado.gov. br>. Acesso em: 3 jan. 2011.

BRASIL. Lei no 12.244, de 24 de maio de 2010. Dispõe sobre a universalização das bibliotecas nas instituições de ensino do país. Disponível em: <http://www.planalto.gov.br/ ccivil_03/_Ato2007-2010/2010/Lei/L12244.htm>. Acesso em: 15 jul. 2011.

CANÊDO, L.B. A classe operária vai ao sindicato. São Paulo: Contexto, 1988.

CHIARELLI, C.A. O trabalho e o sindicato: evolução e desafios. São Paulo: LTR, 2005.

CONSELHO FEDERAL DE BIBLIOTECONOMIA. CFB: 45 anos construindo a história da Biblioteconomia do Brasil! Boletim Eletrônico do Sistema CFB/CRB, v.3, número Especial, 2010. Disponível em: <http://repositorio.cfb.org.br/bitstream>. Acesso em: 4 jan. 2011.

CONSELHO FEDERAL DE BIBLIOTECONOMIA. Boletim. Brasília, 2011. Disponível em: <http://www.cfb.org.br/boletim.php>. Acesso em: 15 jul. 2011.

DAIDONE, D.S.; LUDUVICE, R.V.; SANTOS, V.R. (Org.). CLT e legislação trabalhista complementar. 2.ed. São Paulo: Método, 2001.

DE PLÁCIDO E SILVA. Vocabulário jurídico. Rio de Janeiro: Forense, 1982.

DEPARTAMENTO INTERSINDICAL DE ASSESSORIA PARLAMENTAR. Movimento sindical: passado, presente e futuro. Brasília: [s.n.], 2000.

DEPARTAMENTO INTERSINDICAL DE ESTATÍSTICA E ESTUDOS SOCIOECONÔMICOS. Anuário dos trabalhadores 2008. 9. ed. São Paulo: DIEESE, 2008. Disponível em: <http://www. dieese.org.br>. Acesso em: 15 jan. 2011.

FAUSTO, B. História concisa do Brasil. São Paulo: Imprensa Oficial do Estado, 2002.

FEDERAÇÃO BRASILEIRA DE ASSOCIAÇÕES DE BIBLIOTECÁRIOS, CIENTISTAS DA INFORMAÇÃO E INSTITUIÇÕES. Missão. São Paulo, 2010. Disponível em: <http://www.febab. org.br>. Acesso em: 3 dez. 2010.

GIL, A.C. Como elaborar projetos de pesquisa. 5.ed. São Paulo: Atlas, 2008

INSTITUTO BRASILEIRO DE GEOGRAFIA E ESTÍSTICA. Sindicatos: indicadores sociais 1990, 1991 e 1992: v.4. Rio de Janeiro: IBGE, 1992. Disponível em: <http://biblioteca.ibge.gov. br>. Acesso em: 15 jan. 2011.

INSTITUTO OBSERVATÓRIO SOCIAL. Sindicalismo no Brasil. 2003. Disponível em: <http://www.observatoriosocial.org. br>. Acesso em: 3 jan. 2011.
LIMA, T.C.S.; MIOTO, R.C.T. Procedimentos metodológicos na construção do conhecimento científico: a pesquisa bibliográfica. Revista Katálysis, v.10, número Especial. p.37-45, 2007. Disponível em: <http://www.scielo.br/pdf/rk/v10nspe/a0410s pe.pdf>. Acesso em: 10 jul. 2011.

MARTORANO, M.A.C. Sindicalismo na profissão do bibliotecário. Revista Brasileira de Biblioteconomia e Documentação, v.17, n.1/2, p.79-92, 1984.

MARTINS, H.H.T.S. O Estado e a burocratização do sindicato no Brasil. 2.ed. São Paulo: Hucitec, 1989.

MEMÓRIA da I Reunião Nacional dos Sindicatos de Bibliotecários. Boletim Informativo do Sindicato dos Bibliotecários no Estado do Rio de Janeiro, v.2, n.13-14, 2005.

MINAYO, M.C. (Org.) Pesquisa social: teoria, método e criatividade. Petrópolis: Vozes, 2001.

MORAES FILHO, E. O problema do sindicato único no Brasil: seus fundamentos sociológicos. 2.ed. São Paulo: Alfa Omega, 1978.

OLIVEIRA, M.A. Tendências recentes das negociações coletivas no Brasil. In: SANTANA, M.A.; RAMALHO, J.R. (Org.). Além da fábrica: trabalhadores, sindicatos e a nova questão social. São Paulo: Boitempo Editorial, 2003.

ORDOÑEZ, M.: QUEVEDO, J. Horizontes da história: história para Ensino Médio: curso completo. São Paulo: IBEP, 2005.

PADILHA, L.M. Sindicato de Bibliotecários de MG. [mensagem pessoal]. Mensagem recebida por <leopadilha@gmail.com> em 19 de janeiro de 2011.

PIMENTEL, D.T. O sindicalismo patronal do comércio de bens, serviços e turismo. InfoComércio, v.22, p.10-11, 2010.

RODRIGUES, I.J.; RAMALHO, J.R.; CONCEIÇÃO, J.J. Relações de trabalho e sindicato no primeiro governo Lula (2003-2006). Ciências e Cultura, v.60, n.4, 2008. Disponível em: <http:// cienciaecultura.bvs.br>. Acesso em: 19 fev. 2011

RODRIGUES, L.M. (Org.). Sindicalismo e sociedade. São Paulo: Difusão Européia do Livro, 1968.

RUSSOMANO, M.V. Princípios gerais do direito sindical. 2. ed. Rio de Janeiro: Forense, 2002.

SIMÃO, A. Sindicato e Estado: suas relações na formação do proletariado de São Paulo. São Paulo: Ảtica, 1981.

SINDICATO DOS BIBLIOTECÁRIOS NO ESTADO DO RIO DE JANEIRO. Informativo aos bibliotecários do Estado do Rio de Janeiro. Disponível em: <http://www.sindibrj.org.br/>. Acesso em: 11 fev. 2011.

SINDICATO DOS BIBLIOTECÁRIOS NO ESTADO DE SÃO PAULO. Histórico. São Paulo, 2008a. Disponível em: <http:// www.sinbiesp.org.br/conteudo.php?idsub=3>. Acesso em: 31 jul. 2011.

SINDICATO DOS BIBLIOTECÁRIOS NO ESTADO DE SÃO PAULO. Sobre o sindicato. São Paulo, 2008b. Disponível em: <http://www.sinbiesp.org.br/conteudo.php?idsub=1>. Acesso em: 19 dez. 2010.

TUNES, A. Sindicato de Bibliotecários de MG. [mensagem pessoal].Mensagem recebida por<adritunes@yahoo.com.br> em 12 de fevereiro de 2011.

VIANNA, L.W. Liberalismo e sindicato no Brasil. 3.ed. Rio de Janeiro: Paz e Terra, 1989.

VICENTINO, C.;DORIGO, G. História do Brasil.São Paulo: Scipione, 1998. 